American Journal of Applied Sciences 5 (1): 29-33, 2007

ISSN 1546-9239

(C) 2007 Science Publications

\title{
Road Transport Congestion Costs Calculations Adaptation to Engineering Approach
}

\author{
Marjan Lep and Beno Mesarec \\ University of Maribor, Faculty of Civil Engineering \\ Smetanova 17, 2000 Maribor, Slovenia
}

\begin{abstract}
The article represents so called "engineering" approach for computing the total road transport congestion costs. According to economic welfare theory, the total costs of transport congestion are defined as dead weight loss (DWL) of infrastructure use. With a set of equations DWL could be formulated in a mathematical way. Because such form of equation is not directly applicable for concrete road network calculations it should be transformed into "engineering" form, which comprises transport engineering related data as classified road links, traffic volumes, passenger unit costs, etc. The equation is well applicable on the interurban road network; adaptations are needed for the urban road network cost calculations, where time losses are not so much related to the link travel time. The final equation was derived for the purposes of national road congestion cost calculation.
\end{abstract}

Keywords: transport congestion costs, road network congestion costs, interurban congestion costs, urban congestion

\section{INTRODUCTION}

The EU Commission's proposals for transport infrastructure charging reforms have been presented most extensively in the Green Paper (1995): "Towards Fair and Efficient Pricing in Transport Policy", White Paper (1998): "Fair payment for infrastructure use" and White Paper (2001): "European transport policy for 2010: time to decide". Those proposals imply that each user of transport infrastructure should pay the full marginal social cost imposed by that use, like:

- the marginal cost of infrastructure damages

- the marginal external cost of congestion and scarcity

- the marginal external cost of pollution and

- the marginal external cost of accidents.

It is undeniable that measurement of marginal social costs is complex task. In spite of long studied elements of marginal social costs there are still considerable uncertainties about the true marginal social costs ${ }^{[1]}$.

The term road congestion is frequently used as one of the elements of marginal social costs - but it is still not formally defined. There are a number of different definitions of congestion like:
"The situation when the hourly traffic demand exceeds the maximum sustainable hourly throughput of the link.,"[2] or "Congestion is defined as the impedance vehicles impose on each other, due to the speed-flow relationship, in conditions where the use of a transport system approaches its capacity., ${ }^{,[3]}$

With these two definitions it is possible to reflect the two fundamental approaches to calculating road congestion costs: first one is so called "traffic engineering" approach (which underlies many measures of congestion) and second one is an economic approach (related to principles behind marginal costs of congestion).

Categories of external costs: Non-internalization of transport external costs is causing wrong market signals what results as significant inefficiencies - among the others also as congestion. Based on the welfare maximization approach, the external costs (from individual point of view) are all costs which are not covered by individual traffic user. In measuring the costs of congestion we distinguish three different economic terms of external costs that can be used ${ }^{[4]}$. These are summarized as:

- Total external costs which refer to the sum of external costs within a special area for a specific time period. They represent the sum of individual

Corresponding Author: $\quad$ Marjan Lep, University of Maribor, Faculty of Civil Engineering, Smetanova 17, Postal Code: SI2000, Maribor, Slovenia, Tel: + 38622294 300, Fax: + 38622524179 
external costs related to an actual traffic situation compared to a state of zero congestion. They give us the general idea about the relevance of each cost component per transport mean in order to set policy priorities. A comparison over the time can give us the overview of development of each cost component.

- Average external costs which are equal to total costs divided by number of transport units. They make comparison between different transport means possible. Average external costs are also referring to an actual traffic situation within specific time period. They are interesting for comparison of the cost performance of different transport means.

- Marginal external costs which are equal to the additional cost of an additional transport unit trip. Marginal external costs represents items of marginal cost that are not borne by the transport user (e.g. for road trips they include road wear and tear, increased accident risk and environmental costs). A specific marginal external cost item is "delay to other users", often referred to as the Marginal External Cost of Congestion.

\section{MATERIALS AND METHODS}

Methodology: According to economic welfare theory external congestion costs are defined as dead weight loss. In dense road networks vehicles starts to disturb each other what makes impact on decreasing of travel speeds. That consequently increases the time and operating costs of all users within the system. Each individual impose next to its private costs also additional costs on other users. Those additional costs are called marginal external congestion costs and they are determined by the users' private operating costs as a function of traffic density. Marginal social costs (see Fig. 1) are represented as sum of private operating costs of user and costs which user imposes to the others.

As a consequence of higher external costs, traffic demand will react by shifts in travel times, routes, modes and number of trips. As traffic volume decrease, also the marginal external costs are declining and respectively a part of displaced traffic demand will return to previous behavioural pattern. The resulting equilibrium $\mathrm{Q}^{*}$ (see Fig. 1) is called the optimal traffic demand and the respective marginal external costs are the optimal user charge.

The total costs of transport congestion is according to economic welfare defined as cumulated difference between marginal social costs and the willingness to pay for a particular level of infrastructure quality which is exceeding the optimal level $Q^{*}$. This measure (grey area $\mathrm{ABC}$ on Fig. 1) is called dead weight loss of infrastructure use. As such is considered as only correct economic definition of congestion and can be interpreted as the loss in social efficiency because nonproper use of existing infrastructure ${ }^{[4-6]}$.

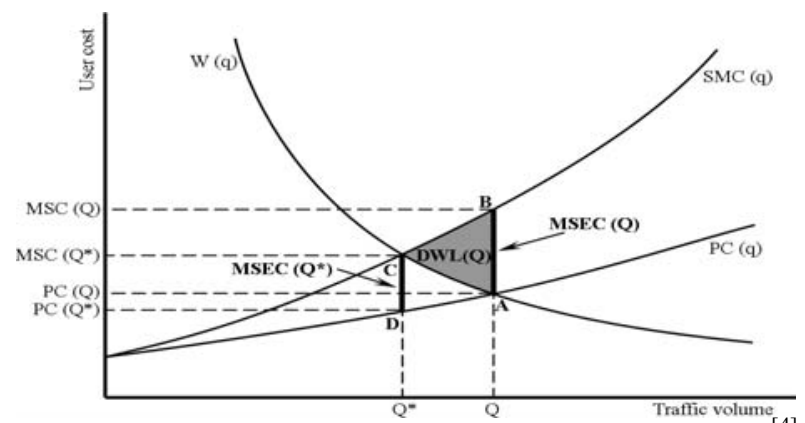

Fig. 1: Economic definition of total congestion costs ${ }^{[4]}$

Total congestion costs represents an artificial measure of ineffective infrastructure use which are based on theoretical reflections on marginal social cost functions rather than on the physical measurement of economic or social damages. There exist a number of approaches to calculate them. The focus will be put to the engineering-type calculations accounting the total user costs below a particular level of road quality.

Total congestion costs are defined by the triangle ABC (see Fig. 1) where is:

- Point "A" - current equilibrium of traffic demand (W) and the private costs each user has to bear (PC).

- Point "B" - intersection of the current traffic demand (Q) and the economically correct user costs - the marginal social costs (MSC).

- Point " $\mathrm{C}$ " - equilibrium state, where marginal social user costs meet that traffic demand, which is adapted to the increased user costs.

In a mathematical way, the problem of determining the dead weight loss for a given infrastructure segment can be formulated by the set of following equations $^{[4]}$ :

$$
\begin{aligned}
& P C(q)=\frac{V O T}{v(q)}+F C(v(q)) \\
& T C(q)=q \cdot P C(q) \\
& \operatorname{MSC}(q)=\frac{\partial T C(q)}{\partial q}
\end{aligned}
$$




$$
\operatorname{MSEC}(q)=\operatorname{SMC}(q)-P C(q)
$$

where is:

$$
\begin{array}{ll}
\text { q } & \text { - traffic volume per time unit } \\
\text { v(q) } & \text { - travel speed } \\
\text { FC(v(q)) } & \text { - speed depending fuel costs } \\
\text { VOT } & \text { - value of time } \\
\text { PC(q) } & \text { - private user costs } \\
\text { TC(q) } & \text { - total costs } \\
\text { MSC(q) } & \text { - marginal social costs } \\
\text { MSEC(q) } & \text { - marginal social external costs }
\end{array}
$$

For the determination of the dead weight loss a demand function $\mathrm{D}(\mathrm{c})$ (where $\mathrm{c}$ is the costs per kilometre a user has to bear) is required. It describes the behaviour of traffic when it has to bear the marginal social external congestion costs. The inverse of $D(c)$ describes the willingness to pay of users for bearing a particular traffic situation - this function is entitled as $\mathrm{W}(\mathrm{q})$. With this function, the deadweight-loss per kilometre and hour of a particular infrastructure segment is described by:

$$
D W L(Q)=\int_{q=Q^{*}}^{Q}(\operatorname{MSEC}(q)-W(q)) \cdot \partial q
$$

where Q denotes the current observed traffic volume and $\mathrm{Q}^{*}$ is the optimal traffic volume at the intersection of $\operatorname{MSEC}(q)$ and $W(q)$.

Because equation (5) is not directly applicable for concrete road network calculations it should be transformed into "engineering" form. On the basis and use of speed-flow relationships, traffic demand elasticises values of time, other operating costs and unit cost functions, approach can be written as ${ }^{[3-5]}$ :

$$
C=\sum_{N} \sum_{T} \sum_{M}\left(L_{N} \cdot Q_{N, T, M} \cdot p_{M} \cdot U C\left(Q_{N, T, M}, p_{M}\right) \cdot V O T_{M, N} \cdot D\right)
$$

where is:

$$
\begin{array}{ll}
\mathrm{C} & \text { - total annual congestion costs } \\
\mathrm{N} & \text { - index of road link } \\
\mathrm{T} & \text { - hour of day } \\
\mathrm{M} & \text { - transport mode } \\
\mathrm{L}_{\mathrm{N}} & \text { - number of lanes of link } \mathrm{N} \\
\mathrm{Q}_{\mathrm{N}, \mathrm{T}, \mathrm{M}} & \text { - traffic volume of mode } \mathrm{M} \text { on link N in } \\
& \text { hour T } \\
\mathrm{p}_{\mathrm{M}} & \text { - passenger - car - units of mode } \mathrm{M} \\
\mathrm{UC}(\mathrm{Q}, \mathrm{p}) & \text { - unit costs per PCU } \\
\mathrm{VOT} & \text { - time - value by mode } \\
\mathrm{D} & \text { - days per year }
\end{array}
$$

Valuing costs of congestion consists from three factors $^{[7]}$ : relationship between travel time and traffic demand (Speed-Flow functions), the valuation of travel time, transport demand function.

Speed-Flow functions describe the relation between the number of vehicles on the road space in particular time segment and the resulting travel speed. On the basis of travel speed and value of time average user costs are computed. On example speed-flow relationship chart three parts are visible (see Fig. 2):

-1 - free flow up to strong interference of vehicles

-2 - strong interference to congestion

- 3 - congestion with low but constant travel speed

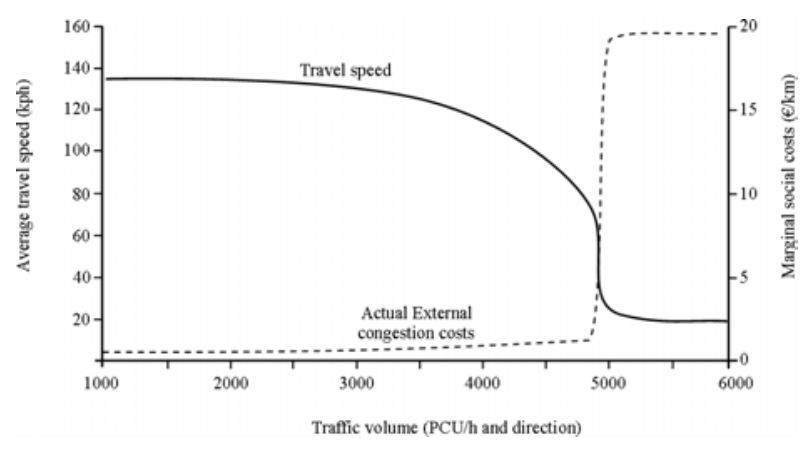

Fig. 2: Example of speed-flow relationship

At low and high traffic volumes the user cost functions are almost flat but on the transition from acceptable to bad traffic conditions is extremely sharp. That implies that the marginal social external costs reach their maximum at the transition from free flow to congestion. Therefore it comes modification of pure social welfare theory:

$\operatorname{MSEC}(Q)=\operatorname{MSEC}\left(Q^{T}\right)$

for $Q>Q^{T}$, where $Q^{T}$ represents the transition traffic volume.

Value of time: The money value of travel time in passenger and goods transport can be quantified by several very different procedures. We distinguish between work time and leisure time spent for transportation purposes. For work time usually wage rate shows the output that could be achieved in the time. Usual approach for leisure time are studies of willingness to pay. For exact calculations the share of trips for work and non-work purposes and vehicle occupancy rates is needed to consider. 
Transport demand functions: The main driving factors of congestion are the costs of individual users which increase with increasing number of road users. This number depends on average user costs. If user charges would be set equal to the actual congestion costs, in theory demand would fall and with it also the external congestion costs. By neoclassical theory the optimal user charges are the marginal external congestion costs at the equilibrium of supply and demand.

\section{Adapted methodology for the road congestion costs} calculation: Concrete calculations of road transport congestion costs in Slovenia for 2002 were made on the basis of previously described methodology with some adaptation. Calculations were made in two parts separately for urban and interurban road network. General equation (6) for congestion costs is directly applicable only for the interurban road network. Calculations were made in two parts - separately for urban and interurban road network as:

$T C=C_{\text {interurban }}+C_{\text {urban }}$

Where TC is total congestion cost for country.

For the urban congestion cost calculation the following equation was used:

$C_{\text {urban }}=\sum \sum T L_{U, P} \cdot V O T_{U, P} \cdot D$

Wherre ${ }^{M T} T L_{\mathrm{U}, \mathrm{P}}$ is the total time loss per urban area and purpose of travel per day, $\mathrm{VOT}_{\mathrm{U}, \mathrm{P}}$ is the value of time per urban area and purpose of travel and D is the number of days per year when congested condition appears. The practical reason for separation of calculation procedure was also the availability of adequate data about road links, traffic volumes on them for each hour of the day per each day in the year, modal split, etc. These data are not available for the urban road network in an adequate amount and accuracy.

The calculation for urban road network was based on the overall area traffic volumes for cars, buses, light duty vehicles and motorcycles in the selected areas, which have the characteristics to be considered as an urban area. For each of these modes shares of trips per purposes and average load factors were calculated. In next phase calculations of shares of trips made in peaktime were made. With consideration of speed difference in peak time and off-peak time the amount of time losses in traffic congestion was assessed. Together with values of time per each trip purpose, the overall value of lost time on Slovenian urban road network was calculated.

\section{RESULTS AND DISCUSSION}

Results for road transport congestion costs for Slovenia in 2002: Cumulative results of transport congestion costs on interurban and urban road network are shown in Table 1.

Table 1: Road transport congestion costs in Slovenia in 2002 (mio $€)$

\begin{tabular}{lccc}
\hline & \multicolumn{3}{c}{ External costs (mio $€$ ) } \\
\cline { 2 - 4 } & $\begin{array}{c}\text { Interurban } \\
\text { road network }\end{array}$ & $\begin{array}{c}\text { Urban } \\
\text { road network }\end{array}$ & Total \\
\hline Motorcycles & 0,1 & 0,3 & $\mathbf{0 , 4}$ \\
Cars & 62,9 & 28,8 & $\mathbf{9 1 , 6}$ \\
Buses & 5,0 & 3,4 & $\mathbf{8 , 4}$ \\
Light duty vehicles & 5,5 & 3,1 & $\mathbf{8 , 6}$ \\
Heavy duty vehicles & 14,5 & 0,0 & $\mathbf{1 4 , 5}$ \\
\hline Total & $\mathbf{8 8 , 0}$ & $\mathbf{3 5 , 5}$ & $\mathbf{1 2 3 , 5}$ \\
\hline
\end{tabular}

Sum of road transport congestion costs in Slovenia in 2002 was 123,5 mio $€$. That represented $0,53 \%$ of national GDP, what is comparable with "old" members of European Union. More than $70 \%$ of that sum contributes external congestion costs on interurban road network. Comparison of transport modes shows that cars (car users) are responsible for $3 / 4$ of all external congestion $\operatorname{costs}^{[8]}$.

\section{CONCLUSION}

Calculations of transport congestion costs are complex task. There are several approaches. Methodology of calculations is developed on the basis of economic welfare theory. But for concrete calculations it must be transformed into "engineering" approach. Applying of that approach is dependent on availability of needed input data, which dictate final form of equations. Such approach was used in study "Analyses of Transport External Costs of Slovenia" for the calculations of external road transport congestion costs. Given results represents values calculated in such way that they are fully comparable with similar calculations over the Europe.

\section{ACKNOWLEDGEMENT}

This research was supported by the Slovenian Ministry of Education, Science and Sport, the Ministry of Transport of the Republic of Slovenia and the Ministry of the Environment and Spatial Planning 
through the Target Research Programme - Slovenian Competitiveness 2006-2013.

\section{REFERENCES}

1. Nash C., Matthews B., 2005. Transport Pricing Policy and the Research Agenda. In: Research in Transportation Economics, Vol. 14 - Measuring the Marginal Social Cost of Transport (ed. C. Nash, B. Matthews) pp. 1-18. Elsevier, Oxford.

2. The Highways Agency (Department for Transport - UK), 1997. Traffic Flow Ranges for Use in the Assessment of New Rural Roads. In: Design Manual for Roads and Bridges, Vol. 5 - Section 5. pp. D/1.

3. Goodwin, P.B., 2004. The Economic Costs of Road Traffic Congestion. pp. 1-26. Rail Freight Group.

4. Banfi S. et al., 2000. External Costs of Transport Accident, Environmental and Congestion Costs in Western Europe pp. 119-136, Infras/Iww, Zürich/Karlsruhe.
5. Nash, C., 2001. Equity Versus Efficiency in Transport Systems. In: Handbook of Transport Systems and Traffic Control (ed. Button K.J., Hensher D.A.) pp. 33-44. Pergamon, Oxford.

6. Calthrop E., Proost S. 1998. CAPRI Final Report Annex A: General Economic Principles of Pricing Transport Services. Centre for Economic Studies, K. U. Leuven, Leuven.

7. Doll C., Jansson J.O., 2005. User Costs and Benefits. In: Research in Transportation Economics, Vol. 14 - Measuring the Marginal Social Cost of Transport (ed. C. Nash, B. Matthews) pp. 125-154. Elsevier, Oxford.

8. Lep M. et al., 2004. Analiza eksternih stroškov prometa. Univerza $\mathrm{v}$ Mariboru, Fakulteta za gradbeništvo, Maribor. 